\title{
O Enoturismo na Região Leste do Estado de São Paulo (Brasil) e na Província de Yamanashi (Japão): Similaridades e Assimetrias
}

\section{Wine Tourism in the Eastern Region of São Paulo State (Brazil) and Yamanashi Region (Japan): Similarities and Asymmetries}

\author{
Geni Satiko Sato (SATO, G. S.) \\ Yasuo Ohe (OHE, Y.) ${ }^{* *}$ \\ Shimpei Shimoura (SHIMOURA, S.) ${ }^{* * *}$
}

\begin{abstract}
RESUMO - A pesquisa caracteriza-se como estudo de caso exploratório do turismo do vinho, da região leste do estado de São Paulo (Brasil) e da região de Yamanashi, localizada na área central do Japão. A pesquisa em São Paulo foi realizada de fevereiro a agosto de 2013 e o dados levantados em Yamanashi, durante o mês de setembro de 2011. Os resultados indicaram que a principal similaridade entre as regiões foi a preferência do turista pelo day tour. Como principal assimetria constatou-se que em Yamanashi os turistas visitavam a região para realizar degustações e tour nas vinícolas enquanto que em São Paulo a visitação ocorria principalmente, durante as festividades da uva e vinho. Outra diferença identificada foi o investimento que as vinícolas de Yamanashi realizaram para fortalecer o vinho Koshu no mercado internacional.
\end{abstract}

Palavras-chave: Enoturismo; São Paulo (Brasil); Yamanashi (Japão).

ABSTRACT - This research is characterized as an exploratory case study of wine Tourism in Eastern region of São Paulo State (Brazil) and Yamanashi, region located in the central area of Japan. The survey in São Paulo was conducted from February to August 2013 and the data and information about Yamanashi, was collected during September 2011. The results indicated that the main similarity between the two regions was the day tour tourist's preference. As main asymmetry was that in Yamanashi, the tourists visited the region for wineries tour and wine tasting and in São Paulo, the tourists came to participate the wine and grape festivities. Another difference was the

\footnotetext{
Formação: Graduação em Engenharia de Alimento pela Universidade Estadual de Campinas (UNICAMP), Mestrado em Economia Agrícola pela Escola Superior de Agronomia Luiz de Queiróz (ESALQ-USP) e Doutorado em Administração de Empresas pela Escola de Administração de Empresas (EAESP-FGV). Atividade profissional: Pesquisador científico do Instituto de Economia Agrícola da Agência de Tecnologia dos Agronegócios, da Secretaria de Agricultura e Abastecimento do Estado de São Paulo (IEA-APTA). Endereço físico para correspondência: Praça Ramos de Azevedo 254, $3^{\circ}$ andar, CEP: 01037-912 - São Paulo/SP - Brasil. Email: sato@iea.sp.gov.br

** Formação: Graduação em Economia Agrícola, Mestrado em Ciências Ambientais e Doutorado em Economia Agrícola pela Hokkaido University. Atividade profissional: Professor do Departamento de Food and Resource Economics da Chiba University, Japão. Endereço físico para correspondência: Department of Food and Resource Economics, Chiba University, 648 Matsudo, Matsudo, Chiba, 2718510, Japan. Email: yohe@ faculty.chiba-u.jp

Formação: Bacharelado em Agronomia pela Tokyo University of Agriculture and Technology, Mestrado em Agricultura e Doutorado em Agricultura pela Kyoto Prefectural University. Atividade profissional: Professor do Departamento de Food and Resource Economics da Chiba Universty, Japão. Endereço físico para correspondência: Department of Food and Resource Economics, Chiba University, 648 Matsudo, Matsudo, Chiba, 271-8510, Japan. Email: shimoura@faculty.chiba-u.jp
} 
investment that was made by the Yamanashi wineries to promote the Koshu wine abroad.

Key words: Wine tourism; São Paulo (Brazil); Yamanashi (Japan). 


\section{INTRODUÇÃO}

O objetivo deste estudo foi identificar as especificidades territoriais e culturais do enoturismo em dois países, Brasil e Japão. A pesquisa caracteriza-se como exploratória e foi conduzida na região leste do Estado de São Paulo e na província de Yamanashi, localizada na área central do Japão (FIGURA 1), sendo as duas regiões, recentes na atividade do enoturismo.

A província de Yamanashi é uma das regiões produtoras de uvas no Japão e também caracteriza-se pela produção de $30 \%$ dos vinhos nacionais (YAMANASHIKANKOU, 2015). A uva Koshu, tem sido explorada pelas vinícolas locais, como principal Vitis vinífera em Yamanashi e o vinho branco Koshu está sendo promovido no mercado global (KOJ, 2015). O enoturismo da região apresenta uma infraestrutura bem evoluída para receber turistas; com estrutura de lojas, áreas de degustação de vinhos e paisagens relacionadas com videiras.

\section{FIGURA 1 - MAPA DA REGIÃO DE YAMANASHI, JAPÃO.}

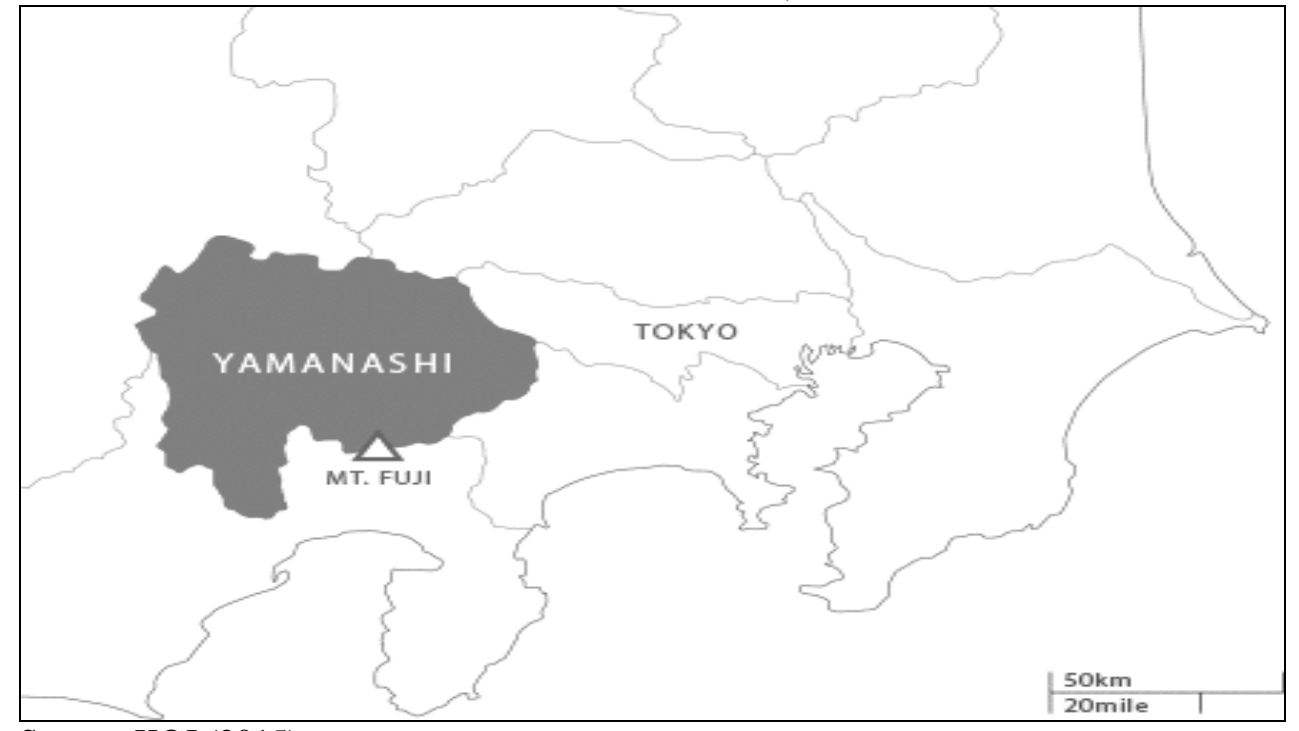

Source: KOJ (2015).

A uva e o vinho Koshu, representam uma tradição na região. A uva trazida do oriente pela rota da seda, está sendo produzida na região desde a Era Meiji e foi desenvolvida para vinhos após o envio de produtores locais para a França, com o objetivo de obter conhecimentos técnicos (KATSUNUMA-WINERY, 2014). Em 2010 foi reconhecida pela Organizaçao Internacional da Vinha e do Vinho (OIV) como uma 
uva Vitis viníferas (TAKAHASHI, 2011). Conforme o mesmo autor, as vinícolas e o governo provincial, vem estimulando a produção das uvas e buscando uma qualidade com padrão internacional para os vinhos locais.

De acordo com dados do Instituto de Economia Agrícola/Coordenadoria de Assistência Técnica Integral - IEA/CATI (2015), no Estado de São Paulo, se produz uvas para mesa e uvas para a indústria. A produção de uvas para a indústria, em 2014, foi de 1.305 toneladas. A região denominada de Escritório de Desenvolvimento Rural (EDR) de Campinas, região leste do Estado, produziu 22,4 toneladas de uvas para a indústria neste mesmo período.

De acordo com Otani (2010) na região leste, do Estado de São Paulo, especificamente no município de Jundiaí, tradicionalmente, se produz vinhos artesanais obtidos da uva de mesa Niágara e, geralmente, com mistura de uvas bordo, adquiridas da região Sul do país.

\section{REFERENCIAL TEÓRICO}

Em 2001, a Organização para a Cooperação e Desenvolvimento Econômico (OCDE, 2001) publicou um relatório sobre conceitos de multifuncionalidades com objetivo de dar suporte para políticas públicas. A agricultura além da função de produção de alimentos, fixar a população na área rural e preservar a paisagem e o ambiente natural pode exercer multifuncionalidades que estão relacionadas com diferentes tipos de serviços e tarefas e outputs não commodities da agricultura.

A multifuncionalidade também tem o compromisso com a qualidade de vida na área rural, o desenvolvimento sustentável e de contribuir para a preservação da tradição nos diferentes espaços territoriais. De acordo com a OCDE (2001) a ação combinada entre os produtos agrícolas e multifuncionalidade é elemento-chave para definir políticas públicas direcionadas para o rural.

A presença de economias de escopo na produção agrícola e as multifuncionalidades propiciam vantagens nos custos e vantagens de competitividade para os produtores, especialmente para os pequenos agricultores que não têm economias de escala. 
De acordo com Machado e Alves (2013), o turismo pode ser entendido como uma prática social com deslocamentos de pessoas em determinado espaço territorial onde ocorrem diversas interações sociais através do consumo. Conforme os autores citados, o ordenamento e a governança deste espaço territorial, por sua vez, ocorre através dos agrupamentos, organização e ações dos turistas, agentes receptivos e poder público. A dinâmica do turismo implícita neste sistema de interações sociais segue uma lógica social e econômica que em geral está relacionada com a lógica de receber bem. (MACHADO; ALVES, 2013).

O turismo rural, conforme Brambatti (2005, p. 41), por sua vez, apresenta-se como as atividades e serviços oferecidos no espaço rural com o objetivo de propiciar aos turistas prazer, experiências, assim como fornecer os produtos localmente produzidos. A área rural apresenta a especificidade de envolver recursos naturais e uma biodiversidade, que devem ser conservados para que o turismo seja sustentável.

Conforme César Dachary (2003) e Basco (2009), o turismo rural, também é representado por muitas atividades diferentes como turismo rural ecológico, turismo de gastronomia, turismo rural histórico, entre muitos outros (CÉSAR DACHARY, 2003, p. 228). Este fenômeno envolve diferentes áreas do conhecimento como a economia, a psicologia, sociologia, antropologia, gestão, educação e ciências naturais (BASCO, 2009, p. 11).

De acordo com Ohe (2008), espaço rural significa onde a atividade produtiva agrícola é realizada com finalidade de oferecer o produto ao mercado e comercializá-lo, atualmente passando por um processo de revitalização através do turismo rural e o turismo educacional, inclusive com a atuação de aposentados que retornam para as áreas rurais.

O conceito do enoturismo no âmbito europeu, de acordo com a Carta Europeia do Enoturismo (GOVERNO DE PORTUGAL, 2015), refere-se a todas as atividades e recursos turísticos, de lazer, sejam de natureza material ou imaterial, relacionados com o vinho e gastronomia autóctone. Este documento surgiu em 2006, no âmbito da Rede Europeia das Cidades do Vinho, com o objetivo de criar normas e parâmetros de qualidade para o enoturismo na Europa.

De acordo com Asero e Patti (2009) o enoturismo é um turismo de experiência criado em torno de um produto e surge do movimento do novo empreendedorismo rural, 
do novo estilo de vida rural, das novas atividades de turismo no espaço rural e de uma cultura de hospitalidade e sustentabilidade. Valduga (2007) identificou que o enoturismo é uma atividade capaz de fortalecer marcas regionais, através de um trabalho endógeno envolvendo agentes locais.

\section{METODOLOGIA}

A metodologia desta pesquisa foi o estudo de casos comparativo (YIN, 2004) com levantamento de campo e aplicação de questionários e entrevistas. Os questionários foram aplicados, entre Fevereiro a Agosto de 2013, na região leste do Estado de São Paulo. O questionário foi composto de questões fechadas, tendo na primeira parte questões sobre preferência para o enoturismo relativamente a outros tipos de turismo, hospedagem, gastos na região e compras de vinhos. Na segunda parte foram coletados dados sócio-demográficos dos turistas.

Dados secundários e informações qualitativas, sobre a região de Yamanashi, foram levantados, durante o mês de Setembro de 2011, período de realização de um estágio técnico de pesquisa realizado em Yamanashi, promovido pela JICA, Japan International Cooperation Agency.

\section{RESULTADOS - REGIÃO LESTE DE SÃO PAULO}

Entrevistas que foram conduzidas na pesquisa, na região Leste do Estado, indicaram que o turismo estava sendo uma opção adicional de renda para produtores de uvas e vinhos (BRAMBATTI, 2005). De acordo com os produtores, a proximidade de São Paulo e de várias cidades do interior, estava sendo uma vantagem, atraindo muitos visitantes e o turismo do vinho na região caracterizando-se pelas festas anuais da uva e vinho, com shows de música, atraindo um perfil diversificado de turistas.

Na pesquisa realizada na região leste do Estado de São de Paulo, contemplaramse, por conveniência, os municipios de Jundiaí, Louveira, Vinhedo e São Roque. 
Também foram aplicados questionários para turistas paulistas que visitavam a região com frequência.

A região leste é conhecida também pelo Circuito das Frutas (FUINI, 2013) e está localizada a uma distância média de 100 km da capital do Estado de São Paulo. Por esta razão, o turismo de um dia e de fim de semana estavam sendo os mais frequentes, de acordo com os proprietários das vinícolas locais.

Verificou-se existir na região forte influência da imigração italiana, conforme mencionado por Otani (2010, p. 25-26), que trouxeram para a região o hábito do consumo diário do vinho. De acordo com Otani (2010, p. 39-40) inicialmente o vinho era produzido para o consumo familiar e, posteriormente, passou a ser comercializado o excedente. Constatou-se que poucas vinícolas conseguiram estruturar suas atividades vinícolas em empresas e a grande maioria sendo constituída de pequenos produtores familiares que estavam produzindo uvas para mesa e vinhos artesanais.

Os dados quantitativos obtidos são estatísticas descritivas da região leste do Estado de São Paulo resultantes da aplicação de cinquenta questionários, durante o período de fevereiro a agosto de 2013. Os resultados indicaram que metade dos turistas (25 respondentes) escolheram o day tour, devido a proximidade de suas cidades de origem. Que 31 dos 50 turistas mencionaram ter comprado mais de 2 garrafas de vinhos na região, 23 disseram ter feito gastos entre $\mathrm{R} \$ 50,00$ a $\mathrm{R} \$ 100,00$ por pessoa. O nível educacional mostrou-se elevado, sendo que 22 dos 50 turistas declararam ter pósgraduação e cerca de metade dos respondentes era do sexo feminino.

Dos turistas analisados, 30 tinham preferência pelo turismo do vinho relativamente a outros tipos de turismo. Questionando os turistas da região do vinho sobre com quem eles costumavam viajar, 21 dos 50 respondentes responderam que com a família.

A renda familiar do turista do vinho mostrou-se bastante elevada, 21 dos 50 respondentes tinham renda entre $\mathrm{R} \$ 2.000,00$ a $\mathrm{R} \$ 4.000,00$. Considerou-se ser esta informação importante, na medida que propicia o consumo local de vinhos e outros produtos. As profissões dos turistas do vinho na região leste eram bastante variadas: funcionários públicos, engenheiros, autônomos, aposentados, escriturários e estudantes. De acordo com os proprietários das vinícolas, eles mencionaram observar que havia crescido a quantidade de ônibus, durante dias da semana, com turistas de terceira idade. 
Para 32 turistas os custos de transporte foram considerados muito importantes e para 31 turistas, também o custo de hospedagem. Custos relativos à alimentação, foram considerados como muito importante para 23 turistas dos 50 respondentes. O custo da degustação foi considerado indiferente para 16 turistas e importante para 15 turistas (TABELA 1).

TABELA 1 - FATORES DE CUSTOS RELEVANTES PARA O TURISTA DO VINHO NA REGIÃO LESTE DO ESTADO DE SÃO PAULO.

\begin{tabular}{l|c|c|c|c}
\hline CUSTOS & $\begin{array}{c}\text { MUITO } \\
\text { IMPORTANTE }\end{array}$ & IMPORTANTE & INDIFERENTE & $\begin{array}{c}\text { NÃO } \\
\text { IMPORTANTE }\end{array}$ \\
\hline Transporte & 32 & 13 & 4 & 1 \\
\hline Alimentação & 23 & 22 & 4 & 1 \\
\hline Vinhos & 11 & 19 & 12 & 8 \\
\hline Hospedagem & 31 & 12 & 5 & 2 \\
\hline Degustação & 7 & 15 & 16 & 12 \\
\hline
\end{tabular}

Fonte: Dados da pesquisa (2013).

O perfil descritivo do enoturista, da região leste de São Paulo, revelou informações relevantes para que os proprietários destas vinícolas pudessem adotar estratégias comerciais e de marketing, para incrementar suas vendas e oferecer uma hospitalidade adequada ao seu perfil socioeconômico.

Durante a pesquisa constatou-se que na região leste os proprietários de vinícolas estavam investindo em paisagismo, lojas temáticas e espaços para degustação com o objetivo de atrair turistas e aumentar a comercialização local, conforme pode-se visualizar nas figuras 2,3 e 4 . 
FIGURA 2 - PAISAGEM DA ENTRADA DA VINICOLA MICHELETTO, REGIÃO LESTE DO ESTADO DE SÃO PAULO.

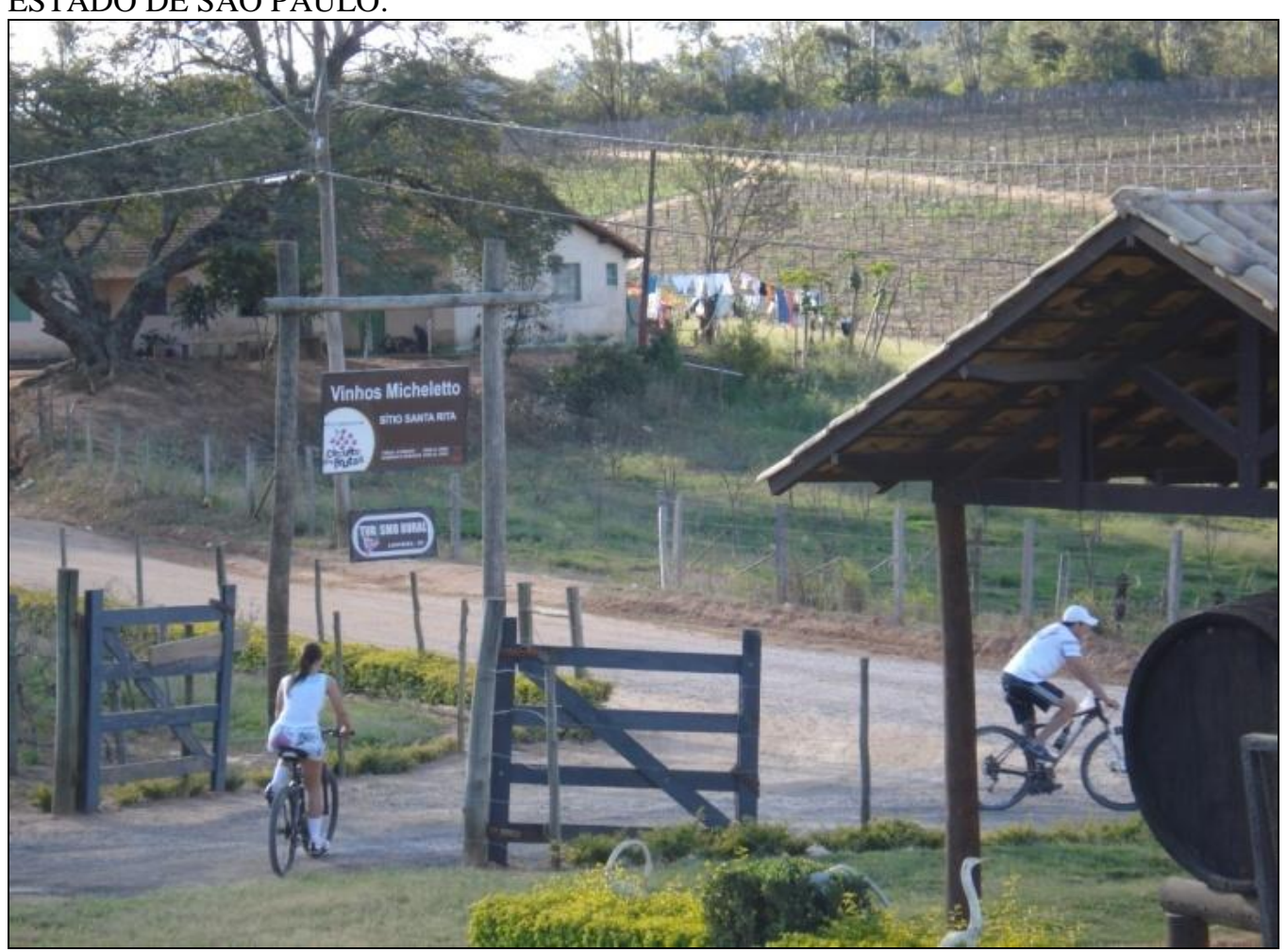

Fonte: Autores (2013).

A Figura 2 apresenta a entrada de uma vinícola em Louveira, com um tonel de carvalho para vinho, próximo ao portão de madeira. O visitante pode visitar a loja de vinhos de bicicleta e fazer degustações de vinhos. A Figura 3 apresenta a vista da vinícola para os parreirais, em período de inverno.

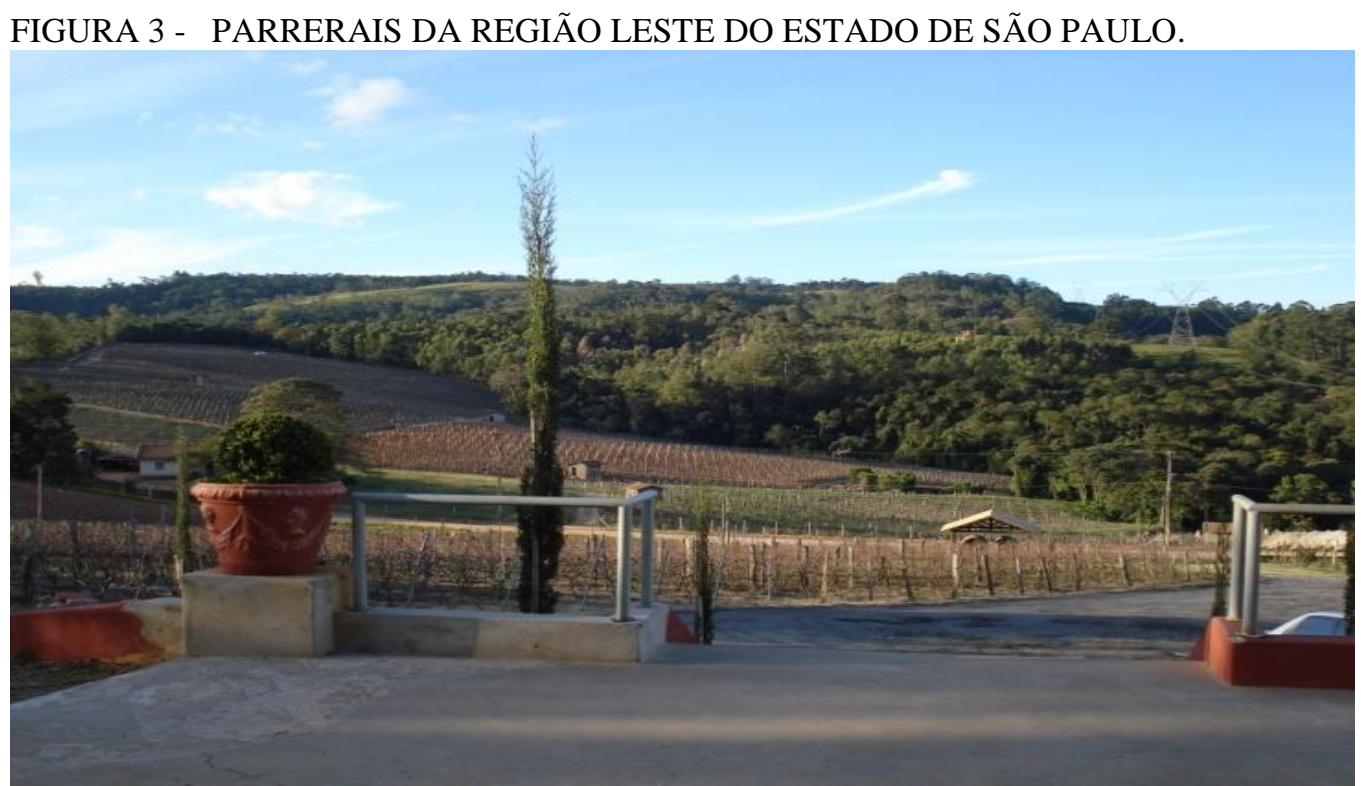

Fonte: Autores ( 2013). 
A Figura 4 apresenta uma loja de vinhos de uma vinícola de São Roque. Durante a visita constatou-se a presença de um sommelier que orientava os clientes sobre as especificações de cada vinho.

FIGURA 4 - LOJA DE VINHOS DE VINICOLA EM SÃO ROQUE, REGIÃO LESTE DO ESTADO DE SÃO PAULO.

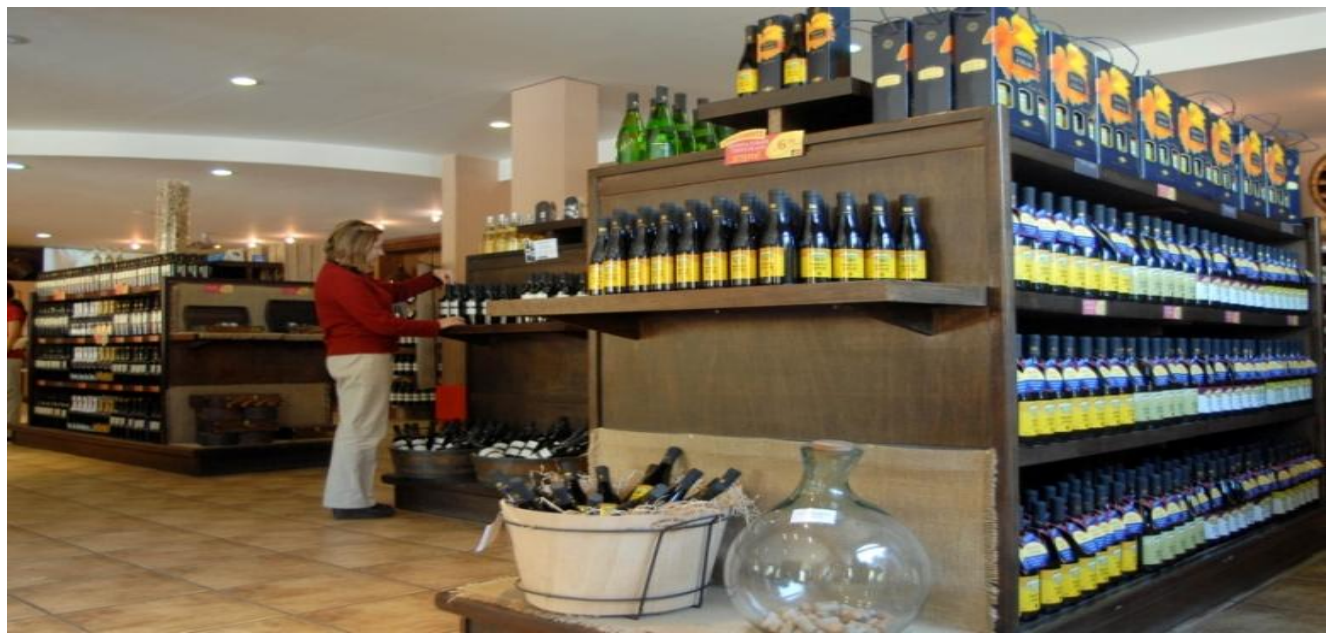

Fonte: Autores, 2013.

Durante a pesquisa foram realizadas visitas às festas da uva e do vinho e constatou-se que estas aconteciam anualmente, em datas diferentes, para cada municipio e, nestas festas estavam sendo comercializados produtos locais tais como frutas, doces, uvas e vinhos, assim como, eram realizadas degustações de vinhos. Para atrair os turistas também eram realizados vários shows musicais durante o período de festividades (PREFEITURA DE JUNDIAÍ, 2015).

\section{RESULTADOS - REGIÃO DE YAMANASHI}

Dados secundários da região de Yamanashi foram obtidos de fontes governamentais e informações qualitativas durante reuniões, entrevistas e visitas técnicas conduzidas durante o mês de setembro de 2011.

Em entrevista com representantes do departamento de agricultura de Yamanashi (2011), foi destacado que muitos produtores locais estavam envelhecendo e, consequentemente, observava-se a redução da produção das uvas, pois estes passavam a trabalhar menos horas por dia. Com o objetivo de atrair os filhos destes agricultores de 
volta à área rural, o turismo do vinho estava sendo estimulado pelo governo com apoio e orientações técnicas.

De acordo com informações coletadas em entrevista com funcionários do departamento de turismo de Yamanashi (2011), durante o período do festival de vinho, em novembro, várias agências de turismo traziam os turistas de Tokyo para um day tour, com pacotes de degustação e roteiros de vinícolas (JTB GLOBAL MARKETING TRAVEL, 2015). O gasto médio diário do turista informado correspondia a cerca de US\$ 100,00 por pessoa.

De acordo com relatório da USDA, United States Department of Agriculture (2014, p. 6-7) o consumidor de vinho no Japão apresentava um perfil de idade, na faixa de 30-40 anos e eram pessoas que faziam cursos de enologia e participavam de jantares de enogastronomia. Em relação, a gênero, o consumo do vinho estava dividido em $50 \%$, entre homens e mulheres, porém, foi observado um interesse pelo vinho, cada vez maior, pelo consumidor feminino; que participava de seminários, degustações e cursos sobre vinhos. Foi constatado que tratava-se de um segmento de consumo muito importante, pois, geralmente, eram elas que decidiam sobre as compras de alimentos e bebidas na família. Observou-se também que as mulheres tinham preferência pelo vinho branco.

Conforme se pode visualizar na Figura 5, o vinho Koshu é um vinho branco e os rótulos, estavam em idioma inglês, para facilitar ao turista estrangeiro a leitura das informações e com o objetivo de direcionar os vinhos para o mercado externo.

FIGURA 5 - VINHOS KOSHU COM ROTULOS EM INGLÊS.

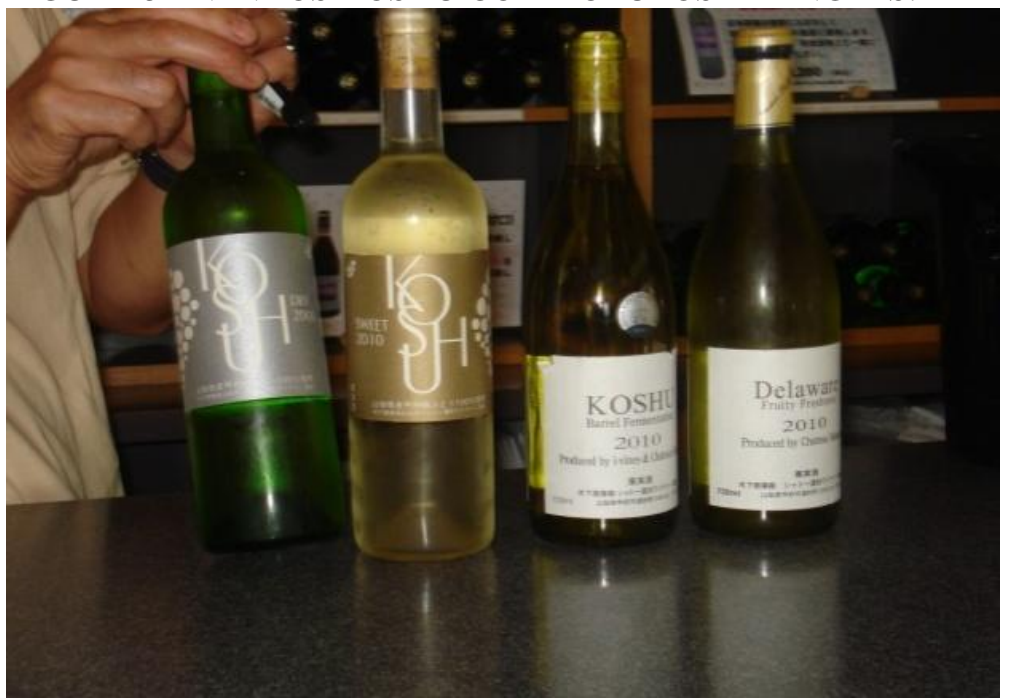

Fonte: Autores (2011). 
Considerou-se como fato singular, em entrevista com técnicos do departamento de turismo de Yamanashi, informarem que o market target para o vinho Koshu, foi identificado como sendo do gênero feminino com idade em torno de 40 anos e elevado nível educacional e profissional.

Como pode-se constatar na Figura 6, as lojas de vinhos na região de Yamanashi, apresentavam um lay out semelhante a qualquer loja de vinho, de qualquer parte do mundo, oferecendo desde vinhos locais como produtos complementares como doces, chocolates e souvenirs.

\section{FIGURA 6 - LOJA DE VINHOS EM, YAMANASHI, JAPÃO.}

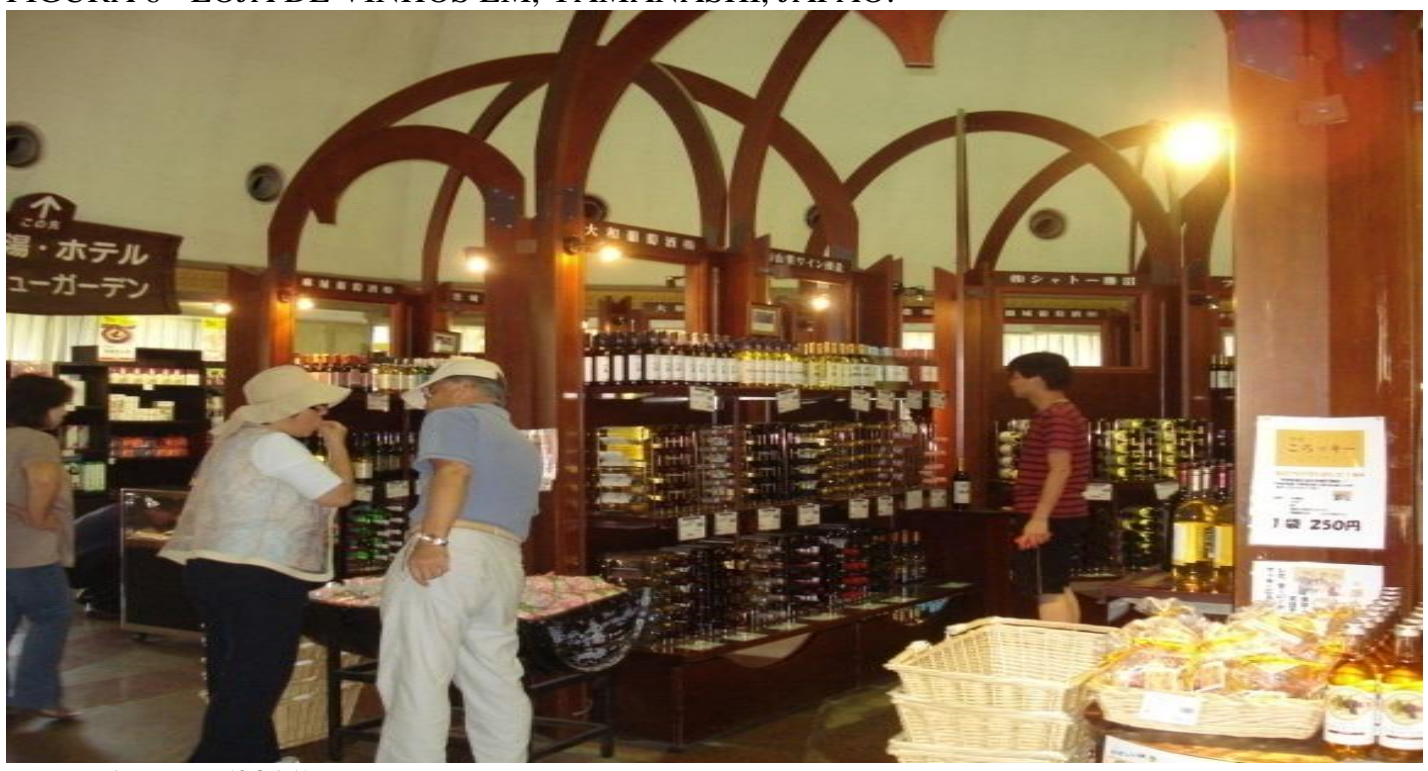

Fonte: Autores (2011).

Constatou-se que os gestores do departamento de agricultura e do departamento de comércio, indústria e trabalho, do governo da província de Yamanashi, estavam promovendo uma série de atividades para valorizar o vinho local através de programas para melhorar a qualidade do vinho e promover o vinho no mercado externo (JAPAN LOCAL GOVERNMENT CENTRE, 2004).

Também que o consumo do vinho importado, cerca de 197.143 kl/ano, em 2011, (FOODEXJAPAN, 2015), era superior a produção doméstica, 93.769kl, mas que estava sendo feito um trabalho para que o consumidor fosse convidado e estimulado a consumir o vinho nacional.

De acordo com dados da secretaria de turismo de Yamanashi, do governo da província de Yamanashi, o número anual de turistas de um dia, em 2008, era de 41,2 
milhões, superior ao do turista de pernoite, 6,3 milhoes, totalizando 47,5 milhões de turistas ao ano. Pode-se constatar pela Figura 8, no período de 1999 a 2008, a tendência da curva ascendente do número de turistas de um dia que visitavam a região.

FIGURA 8 - EVOLUÇÃO DE NÚMERO DE TURISTAS DE UM DIA E TURISTAS COM PERNOITE NA PROVÍNCIA DE YAMANASHI, JAPÃO, 1999-2008.

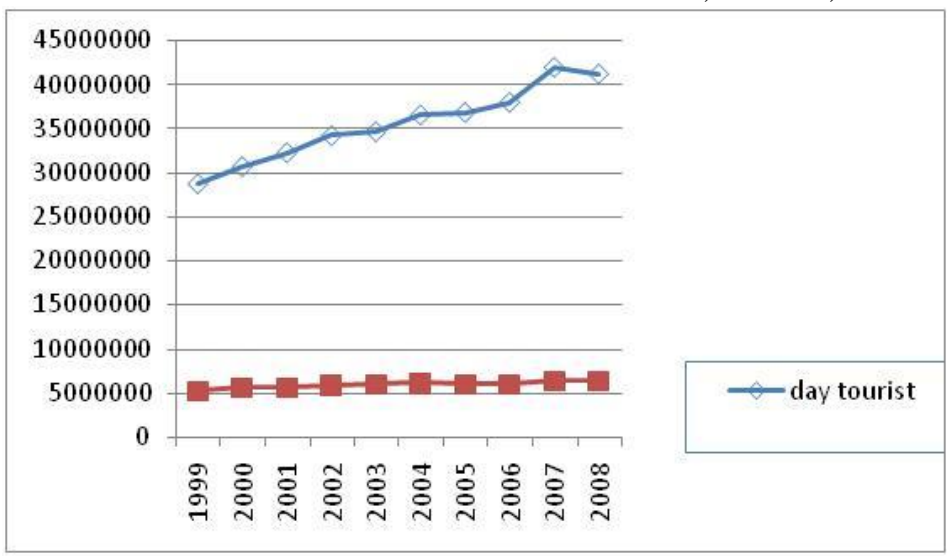

Fonte: Elaborado com dados do departamento de turismo, Governo de Yamanashi, JP (2011, fotocópia).

Verificou-se que os dirigentes do governo provincial e local, juntamente com a comunidade e proprietários das vinícolas de Yamanashi estavam realizando esforços para resgatar aspectos históricos da uva Koshu na região e na valorização do vinho Koshu, no mercado internacional (KOJ, 2015). Estas iniciativas concretizaram-se em 2009, quando foi formada a Koshu of Japan, KOJ, consórcio de 15 produtores, Koshu City Chamber of Commerce, Kofu Chamber of Commerce and Industry and the Yamanashi Prefecture Winemakers Association. Esta organização também participou ativamente para o reconhecimento da uva Koshu como Vitis viníferas e seu registro na OIV, Organização Internacional da Vinha e Vinho (JAPAN LOCAL GOVERNMENT CENTRE, 2014).

\section{CONCLUSÕES}

Deve-se considerar que a análise comparativa entre as duas regiões ficou prejudicada por não estarem finalizados os dados de levantamento de campo para a região de Yamanashi. Com as informações coletadas, até esta fase da pesquisa, pôde-se inferir que a principal similaridade observada entre as duas regiões de turismo do vinho 
em São Paulo e Yamanashi, Japão, foram a proximidade das duas regiões com suas respectivas cidades capitais, o que supostamente, levaria o turista a escolher o day tour.

Como principal assimetria foi constatada que em São Paulo não estava havendo estímulos para produzir uvas Vitis viníferas e, como consequência a qualidade do vinho não estava atingindo padrões internacionais. Por outro lado, o vinho Koshu, produzido em Yamanashi estava obtendo reconhecimento internacional, principalmente na Inglaterra (JAPAN LOCAL GOVERNMENT CENTRE, 2014).

Identificou-se que as festividades da uva e vinho em São Paulo estavam atraindo os turistas com atividades de shows musicais (PREFEITURA DE JUNDIAÍ, 2015) enquanto que, no Japão o turista que visitava a região durante o festival do vinho tinha como objetivo principal conhecer as vinícolas e degustar os vinhos locais.

Constatou-se que em Yamanashi ocorria uma forte participação do governo provincial juntamente às vinícolas para promover o vinho local, no âmbito nacional e internacional. O governo de Yamanashi estava fazendo um trabalho intenso para melhorar a qualidade do vinho e estimular o enoturismo em Yamanashi como forma de atrair filhos de agricultores, de volta à area rural.

Assim exposto, almeja-se que os resultados provenientes desta fase da pesquisa dêem suporte para políticas públicas direcionadas ao turismo do vinho da região leste do Estado de São Paulo com o objetivo de promover o vinho regional e estimular investimentos para aprimoramento da qualidade do produto.

\section{REFERÊNCIAS}

ASERO, V.; PATTI, S. From wine tourism production to wine tourism experience: the case of Italy. AAWE WORKING PAPER, n. 52. November. 2009.

BASCO, C. A. Diagnóstico de turismo rural en el Brasil. Instituto Interamericano de Cooperación para la Agricultura. IICA. 2009. Disponível em: $<$ http://www.iica.int/Esp/organizacion/LTGC/agroturismo/Documentos\%20Agroturism o/Diagn\%C3\%B3stico\%20de\%20Turismo\%20Rural\%20en\%20el\%20Brasil.pdf $>$. Acesso em: janeiro/2015. 
BRAMBATTI, L. E. Racionalização, cultura e turismo em meio rural na serra gaúcha. Tese de doutorado. 227 p. Universidade Federal do Rio Grande do Sul. Porto Alegre. 2005.

CÉSAR DACHARY, A. Rutas, culturas y cotidianidad en el mundo rural. In: SEMINÀRIO TURISMO RURAL Y SU CONTRIBUCIÓN A LA CREACIÓN DE EMPLEO Y A LA CONSERVACIÓN DEL PATRIMONIO: capítulo III. 12 y 13 maio, Asunción (Paraguay). 2003. Disponível em:

<http://www.idestur.org.br/download/20120219145259.pdf>. Acesso em: janeiro/2015.

DEPTO DE AGRICULTURA, GOVERNO DE YAMANASHI. Fotocópias de tabelas de dados de produção de uva e vinhos. 2011.

DEPARTAMENTO DE TURISMO, GOVERNO DE YAMANASHI. Fotocópias de tabelas de dados de turistas day tour e overnight. 2011.

FOODEXJAPAN2015. Wine market continues to expand. Disponível em: <http://www3.jma.or.jp/foodex/en/sc/category14.html>. Acesso em: janeiro/2015.

FUINI, L. L. Os circuitos turísticos como manifestações atuais. In: ENCONTRO NACIONAL DA ASSOCIAÇÃO DE PÓS GRADUAÇÃO EM PLANEJAMENTO URBANO E REGIONAL, 2013, Recife. Anais do encontro nacional da Anpur Desenvolvimento, planejamento e governança: Recife. V. 15, p. 1-17.

GOVERNO DE PORTUGAL. Carta Européia do Enoturismo. Disponível em: $<$ http://www.turismodeportugal.pt/Portugu\%C3\%AAs/AreasAtividade/desenvolviment oeinovacao/ReuniaoTecnicaEnoturismo/CataEuropeiadoEnoturismo/Pages/CartaEurope iadoEnoturismo.aspx> . Acesso em: janeiro/2015.

JAPAN LOCAL GOVERNMENT CENTRE, (2014). Yamanashi Prefecture Promotes Regional Produce at 3rd Annual London Koshu Wine Annual Trade and Press Fair. Disponível em: <http://www.jlgc.org.uk/en/news_letter/yamanashi-prefecturepromotes-regional-produce-at-3rd-annual-london-koshu-wine-annual-trade-and-pressfair/>. Acesso em: janeiro/2015.

IEA/CATI. Banco de dados. Disponível em: <http://ciagri.iea.sp.gov.br/nia1/subjetiva.aspx?cod_sis=1\&idioma=1>. Acesso em: janeiro/2015. 
JTB GLOBAL MARKETING TRAVEL (2015). Yamanashi prefecture promotes regional produce at 3rd annual London Koshu Wine Annual Trade and Press Fair. Disponível em: 〈http://www.jtbgmt.com/en/plan/fuji_08/>. Acesso em: janeiro/2015.

KATSUNUMA WINERY. Disponível em: <http://www.katsunumawinery.com/english/pg/koshupg/koshu.html>. Acesso em: fevereiro/2014.

KOJ. Disponível em: <http://koshuofjapan.com/region/index.html>. Acesso em: fevereiro/2015.

MACHADO, S. F.; ALVES, K. S. O turismo em Ouro Preto - Minas Gerais, Brasil - na perspectiva dos moradores. Turismo \& Sociedade. Curitiba, v. 6, n. 3, p. 552-573, julho de 2013.

OCDE. Organização para a Cooperação e Desenvolvimento Econômico. Multifunctionality towards an analitical framewords. OCDE Publ. Service. Paris, France. 2001. p. 1-25. Disponível em: <http://www.oecd.org/tad/agriculturalpolicies/40782727.pdf>. Acesso em: janeiro/2014.

OHE, Y. Impact of rural tourism operated by retiree farmers on multifunctionality: evidence from Chiba, Japan. Asia Pacific Journal of Tourism Research, v. 13, n. 4, p. 343-356, December 2008.

OTANI, M. N. Estratégias de reprodução social em áreas periurbanas: os produtores de vinho artesanal comercial em Jundiaí. 114 p. Dissertação de Mestrado. Faculdade de Engenharia Agrícola. UNICAMP. 2010.

PREFEITURA DE JUNDIAÍ. Programação completa da 32a . Festa da Uva de Jundiaí. Disponível em: <http://www.jundiai.sp.gov.br/noticias/2015/01/15/programacaocompleta-da-32a-festa-da-uva-de-jundiai/> . Acesso em: fevereiro/2015.

TAKAHASHI, T. (2011). Production and consumption wine in Japan. ASSOCIATION INTERNATIONALE DES JURISTES DU DROIT DE LA VIGNE ET DU VIN (AIDV) CONFERENCE, 24-26 out, 2011, Rioja, Espanha: Session 8. Disponível em: <http://www.juban.fr/_media/teiji-takahashi.pdf>. Acesso em: janeiro/2015.

USDA. United States Department of Agriculture. Japan Wine Annual. USDA Global Agricultural Information Network. Gain report, number JA4503. 2014.

VALDUGA, V. O processo de desenvolvimento do enoturismo no Vale dos Vinhedos. 151 p. Dissertação de Mestrado. Universidade de Caxias do Sul. 2007. 
YAMANASHI-KANKOU. Winery experience. Disponível em:

<http://www.yamanashi-kankou.jp/umaiinet/facility/wine/> Acesso em janeiro/2015.

YIN, Robert K. Estudo de casos: planejamento e método. 3. ed. Porto Alegre: Bookman. 2004.

Recebido em: 28-03-2014.

Aprovado em: 27-04-2014. 